\title{
Hubungan Islam dan Sains: Tawaran Syed Muhammad Naquib Al-Attas
}

\section{Muhammad Taqiyuddin}

Universitas Darussalam Gontor, Email: taqiyuddin@unida.gontor.ac.id

\begin{abstract}
Abstrak
Secara umum, kajian tentang hubungan antara Islam dan Sains diinisiasi oleh tokoh seperti Holmes Rolston, John F Haught, Ian G Barbour, juga Huston Smith. Alternatif Integrasi selalu dipilih sebagai hubungan tersebut. Lebih mutakhir lagi, adalah integrasiinterkoneksi yang diinisiasi oleh Amin Abdullah. Kajian tersebut memungkinkan adanya ruangan untuk metodologi studi agama dan sains secara lebih multidisipliner. Jika melihat berbagai kajian tentang integrasi tersebut, tujuannya adalah perumusan Sains yang berbasis teologis; yakni Sains Islam. Meski, sejatinya ide tentang Sains Islam sudah inheren dalam pemikiran al-Attas tentang Islamisasi Ilmu. Hal inilah yang mendorong perlunya kajian yang memetakan posisi integrasi dan tawaran al-Attas tentang Sains Islam. Kajian ini bersifat filosofis berbentuk kualitatif (kajian pustaka) berupa survei atas beberapa kajian integrasi serta meninjau secara kritis tawaran Sains Islam al-Attas. Pembahasannya dimulai dengan pemaknaan Sains dan Islam secara semantik ditambah analisa historis atasnya. Kajian ini setidaknya menyimpulkan bahwa paradigma integrasi sebagai hubungan antara Islam dan Sains sejatinya merupakan tahapan awal yang terjadi saat awal mula perkenalan Islam dengan peradaban lain. Yang mana, paradigma Sains Islam sejatinya merupakan kajian mutakhir hasil kegiatan intelektual kreatif dari peradaban Islam. Meskipun, paradigma sains Islam masih banyak memerlukan suplai metodologi dan kajian pendukung berupa perumusan program riset sebagai rahim dari Sains Islam tersebut.
\end{abstract}

Kata kunci : Islam; Sains; Integrasi; Islamisasi; Sains Islam

Abstract

In general, the study of the relationship between Islam and Science was initiated by figures who talked about religious and scientific relations such as Holmes Rolston, John F Haught, Ian G Barbour, as well as Huston Smith. Alternative Integration is always chosen as the relationship. Even more recent, is the interconnection-integration initiated by Amin Abdullah. The epistemological study allows for more multidisciplinary space for religious and scientific study methodologies. If you look at various studies about integration, the aim is the formulation of 
science based on theological; namely Islamic Science. Although, the true idea of Islamic Science is inherent in al-Attas's thoughts on the Islamization of Science. This is what drives the need for studies that map the position of integration and al-Attas's offer of Islamic Science. This study is philosophical in the form of qualitative (literature study) in the form of a survey of several studies of integration and critically reviewing al-Attas's Islamic Science offer. The discussion begins with the semantic meaning of Science and Islam plus a historical analysis of it. This study at least concludes that the paradigm of integration as the relationship between Islam and Science is actually the initial stages that occur when the initial introduction of Islam with other civilizations. Which, the Islamic Science paradigm is actually a recent study of the results of creative intellectual activities of Islamic civilization. Although, the paradigm of Islamic science still requires a lot of supply of methodologies and supporting studies in the form of the formulation of research programs as the womb of Islamic Science.

Keywords : Islam; Science; Integration; Islamization; Islamic Science

\section{Pendahuluan}

Diskursus hubungan antara agama dan sains selalu menjadi wacana diskusi yang menarik. Sains dalam kehidupan manusia selalu berkembang dan berubah. Sedangkan agama selalu dianggap tradisi turun temurun yang dipertahankan oleh masyarakat tertentu. Sains dan teknologi saat ini mencapai perkembangan yang sangat pesat, bahkan seolah tidak pernah terprediksikan sebelumnya. Sains dan teknologi di Barat seperti mesin uap, komputer, mekanika, dan lainnya mengalami perkembangan pesat pada abad 17-18 (FYFE, 2005; Toby E. Huff, 2017). Sejak revolusi keilmuan terhadap otoritas keagamaan pada abad 12-13.(Toby E. Huff, 2017, pp. 72-76) Sejak saat itulah sains memisahkan diri dari otoritas keagamaan Kristen. Meskipun sebagian dari sains tetap berkembang bersama agama Kristen (Brooke, 2014; Karamustafa, 2017).

Negara-negara yang saat ini sangat berkontribusi dalam sains dan teknologi saat ini mayoritas merupakan negara-negara Barat. Hal ini sudah menjadi fakta yang empiris, dari segi penelitian dan akademik, fasilitas umum milik masyarakat, ketertiban umum, dan lainnya selalu mengesankan orang luar yang berkunjung ke tempat tersebut. Perkembangan sains juga diikuti oleh perkembangan paradigma manusia yang ada (Ynalvez and Shrum, 2015). Perkembangan sains dan teknologi bukan tanpa masalah. Banyak penelitian yang mendalam mengenai dampak jangka panjang dari pesatnya perkembangan sains tersebut. Matthew Orr memberikan sebuah ilustrasi dari penelitian mengenai pengaruh aspek manusia dalam problem perubahan iklim dunia (Orr, 2006; HOUGHTON, 2011; De Witt et al., 2016). 
Dari paparan tersebut, muncul adanya ide untuk mensintesakan ajaran-ajaran dan etika yang ada pada agama ke dalam aktifitas saintifik untuk mengendalikan perkembangan teknologi tersebut. Para saintis dan agamawan di Amerika pernah mendiskusikan perlunya integrasi sains dan agama. Penggunaan ilmu pengetahuan dan teknologi yang tidak dibatasi dengan moral dan etika, sudah terbukti banyak merugikan kehidupan manusia. Manusia membutuhkan pedoman berupa nilai moral dalam perkembangan teknologi tersebut (Orr, 2006; Ellis, 2012).

Lain halnya dengan pengalaman sains dan agama dalam dunia Islam. Agama yang dibawa oleh Rasulullah SAW bahkan secara epistemologi menekankan adanya kewajiban untuk menuntut ilmu dalam rangka mengenali keberadaan Allah. Sejarah telah mencatat tradisi keilmuan pada masa peradaban Islam sangatlah berkembang, namun tidak lantas "menaikkan bendera revolusi" terhadap otoritas keagamaan yang ada. Banyak juga para ahli sejarah sains Barat mengakui hal tersebut. Bahkan tradisi keilmuan di Andalusia juga turut bersumbangsih dalam membawa Eropa kepada Abad Pencerahan (Von Grunebaum, 2013; Bakar, 2016a, pp. 16-17). Hubungan yang integratif tersebut, memang inheren dalam pandangan alam Islam (Islamic Worldview) yang menjadi kerangka berfikir yang menjadi alternatif dalam menjelaskan proporsi, karakteristik, hingga titik temu keduanya. Bahkan, tidak aneh jika disebut bahwa aqidah Islam adalah induk dari keberadaan sains Islam di masa lampau tersebut. Yang mana, proses intelektual tersebut tetap berjalan hingga masa sekarang ini (Muslih, 2017a).

Sebenarnya, kajian tentang hubungan Islam dan sains telah menjadi topik hangat dalam berbagai penelitian. Beberapa kajian, secara umum telah mengupasnya dari perspektif hubungan agama dan sains di era kontemporer. Kajian oleh Zaprulkhan misalnya, menekankan bahwa agama dan ilmu pengetahuan dapat dipadukan secara proporsional. Khususnya terkait dengan fungsinya masing-masing. Sehingga, pendekatan pada keduanya dilakukan melalui diskursus metodologi pada kebutuhan dan ruang lingkup masingmasing. Ini mengikuti tawaran pendapat Holmes Rolston, John F Haught, Ian G Barbour, juga Huston Smith. Kesemuanya membuka kemungkinan argumen hubungan agama dan sains yang berbasis integrasi. Yang mana menekankan agar sains membuka diri untuk mendapat penjelasan secara agamis, dan agama perlu membuka diri agar segala kepercayaan dan sistem keyakinan dapat diuji secara ilmiah (Zaprulkhan, 2013). 
Kajian tentang integrasi yanglebih spesifik, dilakukan oleh SyarifHidayatullah. Yang secara khusus menjelaskan tentang relasi dan metodologi dalam sains dan agama. Secara umum, pembahasannya tidak jauh berbeda dengan kajian mengenai hubungan sains dan agama oleh Zaprulkhan. Namun yang menjadi lebih menarik, kajian ini menyebutkan beberapa tokoh yang merupakan representasi ilmuwan muslim; yang secara khusus menyebut tawaran kemungkinan bahwa Islam dan sains merupakan satu kesatuan yang saling menjelaskan. Hal ini, menunjukkan adanya metodologi dan paradigma baru sebagai kemungkinan adanya sains teologis; yakni Sains Islam (Islamic Science) (Hidayatullah, 2019). Kajian serupa dan lebih mutakhir, sejatinya telah didahului oleh M Amin Abdullah. Yang secara khusus menyoroti aspek yang lebih mendalam dari sekedar integrasi, yakni adanya interkoneksi antara sains dan agama. Yang mana, memungkinkan keduanya mampu berdialog dan saling menjelaskan secara multi disiplin, interdisipliner, dan transdisipliner. Hal ini dimaksudkan agar masing-masing disiplin ilmu tidak menjadi sempit karena tujuan linearitas keilmuan; yang seringkali menjadikan tafsir atas agama dan sains menjadi tidak relevan. Tawaran integrasi interkoneksi ini, secara luas berfungsi menyediakan ruang untuk mengkonstruksi metodologi keilmuan dan metode studi agama (Abdullah, 2014).

Tawaran integrasi-interkoneksi, mendapat gayung yang bersambut dari Mohammad Muslih. Yang secara khusus mendalami Filsafat Ilmu dengan fokus penelitian tentang aspek program riset pada sains. Hal ini secara runtut ditawarkan dalam berbagai serial kajiannya berdasarkan integrasi-interkoneksi pada tahapan yang lebih lanjut, yakni adanya sains berbasis teologis. Hal ini sangat penting, mengingat bahwa Islam dan sains seringkali dihubungkan secara tidak relevan. Misalnya, melalui metode justifikasi atau ayatisasi dan metode lainnya yang berpotensi mereduksi makna Sains Islam menjadi 'pseudo-sains' (sains palsu). Sehingga, problem tersebut perlu diatasi dengan merancang secara detail suatu tawaran program riset yang menyediakan ruang bagi dimensi teologi agar menjadi dasarnya (Muslih, 2016, 2017b, 2019, 2020).

Ada similaritas yang menarik. Keseluruhan kajian tersebut dimulai dari problematika pengalaman hubungan agama dengan sains modern di Barat dalam sejarahnya. Yang sejatinya, didahului dengan semangat sekularisasi terhadap agama pada masa itu. Analisa ini sejatinya telah lebih lama disampaikan oleh Syed Muhammad Naquib al-Attas, yakni seorang filsuf Melayu yang menguasai disiplin 
ilmu bidang filsafat sains Islam. Tawarannya adalah penyelarasan pendapat tentang adanya hubungan antara Islam dan sains, yang sebagaimana telah dijelaskan secara terpisah oleh beberapa ilmuwan sebelumnya. Makalah ini berusaha untuk mengungkapkan relevansi tawaran al-Attas tentang keberadaan paradigma 'Sains Islam' sebagai wujud hubungan sains dengan agama Islam dalam konteks kajian mendalam terhadap epistemologi, tren, dan pemaknaan sains dalam Islam yang akan didahului dengan kajian mengenai tradisi sains dan ilmu di Barat.

Penelitian ini merupakan kajian pustaka (Given, 2008; Fletcher, 2015) dengan mengumpulkan data melalui survei literatur yang secara khusus menyoroti aspek filosofis makna sains dan agama di Barat dan Islam secara komparatif; baik perbedaan maupun persamaan antara keduanya. Lebih lanjut, kajian ini turut mengelaborasi sekilas pemikiran al-Attas tentang Filsafat Sains Islam yang berfungsi sebagai basis teologis adanya Sains Islam. Analisa data dilakukan melalui klasifikasi makna dan karakter sains dan agama secara historis-filosofis dengan metode compare and contrast (Gibson and Brown, 2011) dan analisa diskursus (discourse analysis) (Fletcher, 2015) atas tawaran al-Attas, yakni pemikirannya tentang keberadaan Sains Islam sebagai sains yang memiliki paradigma, agenda, dan telah menjadi fakta sejarah di masa lalu.

\section{Pembahasan}

\section{Syed Muhammad Naquib al-Attas}

Sebelum mengungkap lebih banyak tentang pemikiran metafisika al-Attas, akan lebih baik bila ada ulasan singkat tentang riwayat hidupnya. Syed Muhammad Naquib bin Ali bin Abdullah bin Muhsin Al-Attas (nantinya akan disebut al-Attas saja) termasuk pemikir muslim kontemporer yang tersohor. Lahir 5 September 1931 di Bogor, Jawa Barat, Indonesia (Muhammad, 2009, p. 74; Widodo, 2009) Ia juga sebagai keluarga Ba'lawi dengan silsilah sampai kepada Imam al-Husayn, cucu Rasulullah Saw. Kakeknya dari pihak ayah adalah Syed Abdullah ibn Muhsin ibn Muhammad al-Attas, seorang wali yang pengaruhnya mencakup Indonesia dan tanah Arab. Hingga saat ini, makam kakeknya yang terletak di Bogor senantiasa diziarahi oleh kaum muslimin. Masjid an-Nur (didirikan tahun 1815) terletak di samping makam tersebut (Al-Alam, 2017a, pp. 7-8).

Ibu al-Attas bernama Syarifah Raguan al-Aydrus, yang merupakan 
keturunan ningrat Sunda di Sukapura. Al-Attas adalah anak kedua dari tiga bersaudara. Kakaknya bernama Syed Hussein al-Attas, sosiolog dan mantan Rektor Universitas Malaya. Adiknya, Syed Zain al-Attas adalah seorang insinyur kimia dan mantan dosen Institut Teknologi di MARA (Malaysia) (Alatas, 2013, p. 11; Al-Alam, 2017b). Al-Attas lahir di tengah keluarga berpendidikan tinggi. Pendidikan formalnya dimulai pada usia 5 tahun di Ngee Hong Johor Primacy School Malaysia pada masa pendudukan Jepang. Selanjutnya, ia menimba ilmu di Madrasah Al-'Urwatu'l- Wuthqā Jawa Barat sembari mendalami bahasa Arab. Usai perang dunia ke-II, ia kembali ke Johor di tahun 1946 untuk melengkapi sekolah lanjutan; yang pertama di Bukit Zarhroh School dilanjutkan di English College (1946-1951). Di Malaysia, ia hidup bersama pamannya, Ungku Abdul Aziz bin Ungku Abdul Majid yang masih sepupu dari Sultan. Selanjutnya, pamannya menjadi Menteri ke-6 di Johor Modern (Al-Alam, 2017b, p. 8).

Bersama pamannya, al-Attas berkesempatan mengeksplorasi literatur Melayu berupa sejarah, agama, dan pemikiran Barat yang terdapat di perpustakaannya. Pada masa inilah, al-Attas mengasah kemampuan menulis dan mendalami sastra Melayu dengan berbagai asal-usul kosakatanya. Usai sekolah menengah di tahun 1951, ia masuk resimen Malaysia sebagai kadet dengan nomor 6685 (Muhammad, 2009, p. 140) Al-Attas terpilih untuk mengikuti pendidikan militer di Eaton Hall, Chester; untuk selanjutnya berkarir di Royal Military Acedemy Sandhurst, Inggris (1952-1955). Pengalaman inilah yang membentuk spirit dan bahasa Inggrisnya; sembari melajutkan kegemarannya dalam mengeksplorasi literatur perpustakaan di sana. Pada masa ini, al-Attas menekuni pembahasan tentang metafisika suf; khususnya al-Jāmī, seorang sufi muslim; yang karyanya dapat diakses melalui perpustakaan di sana. Pada masa tersebut, al-Attas gemar mengadakan perjalanan ke seputar negara Eropa; khususnya Spanyol hingga juga benua Afrika guna melihat dan mengamati peninggalan kejayaan Islam di masa lampau. Pengalaman tersebut sangat terpatri dan mempengaruhi semangat dan etos ilmiah; selanjutnya mendorongnya untuk mengundurkan diri dari karir militer dan melanjutkan di University of Malaya di Singapura tahun 1957-1959.

Saat masa studinya di University of Malaya, al-Attas telah menulis beberapa karya. Sebuah karya tentang syair Melayu, yakni Rangkaian Ruba iyat (1959) dan tentang sufisme berjudul Some Aspects of Süfism as Understood and Practised among the Malays (1963). Karena etos ilmiah itulah, ia mendapat penghargaan 
dari the Canada Council Fellowship untuk mengambil master di Institute of Islamic Studies, McGill University Montreal (Muhammad, 2009, pp. 74-75) AlAttas menyelesaikan kuliah Magisternya dalam bidang Islamic philosophy tahun 1962 dengan Tesis berjudul Ranini and the Wujüdiyyah of 17th Century Acheh. Al-Attas kemudian melanjutkan studi doktoralnya di the University of London in the School of Oriental and African Studies (SOAS), di mana tesis doktoralnya di tahun 1965 dibimbing orientalis masyhur; prof. A. J. Arberry dari Cambridge dan Dr. Martin Lings. Karya doktoralnya, berupa dua volume buku berjudul The mysticism of Hamzah Fansūrì. Di tahun yang sama, Al-Attas kembali ke Malaysia dan menjadi Kepala Divisi Literatur (Head of the Division of Literature) pada Department of Malay Studies di University of Malaya, Kuala Lumpur (Al-Alam, 2017b).

Tawaran al-Attas untuk hubungan antara Islam dan sains tergolong filosofis. Pasalnya, al-Attas menguraikan pendapatnya tentang Sains Islam sebagai perspektif dan paradigma keilmuan. Hal ini linear dengan pemikirannya tentang Islamisasi Ilmu Pengetahuan Kontemporer. Secara definitif, Islamisasi adalah 'pembebasan manusia dari kungkungan mitos dan kontrol bahasa yang sekuler yang membelenggu kebebasan akal dan keyakinannya kepada hal-hal yang nyata dan benar (Salomon, 2013; Nurdin, 2016; Maulana, 2018). Al-Attas seperti ingin mengungkapkan, bahwa Islam sebagai dìn memiliki visi sebagaimana para nabi dan rasul terdahulu, yakni membebaskan manusia dari mitos dan kepercayaan yang tidak benar. Hal ini menegaskan pemikiran al-Attas tentang 'pandangan alam Islam' (Islamic Worldview) yang disebut sebagai rujyatu al-Isläm lil wujüd; yakni visi Islam tentang realitas dan kebenaran yang diderivasi dari wahyu alQur'an pada din al-Islam melalui kenabian Muhammad saw. Di masa selanjutnya, wahyu membentuk secara sistemik peradaban Islam yang pernah berjaya pada sejarahnya (al-Attas, 1995; Dzulhadi, 2015).

Menurut al-Attas, yang menjadi problem bagi umat Islam di era kontemporer adalah ketiadaan adab (loss of adab) dan kerusakan ilmu' (corruption of the knowledge). Karena itulah, ia menawarkan konsep ta'dì $b$ sebagai filsafat pendidikan Islam yang mengandung aspek tarbiyah dan ta'lim sekaligus (Ardiansyah et al., 2017; Ismail, 2017) Kedua masalah di atas, mengakibatkan kebingungan (confussion) intelektual yang secara luas mengabaikan keadilan dan otoritas keilmuan yang benar. Di antaranya kebingungan itu mengakibatkan kemunculan produk ilmu 
pengetahuan dan sains yang tidak bertanggungjawab terhadap kelangsungan lingkungan hidup manusia; dengan alasan, bahwa ilmu pengetahuan adalah netral dan universal. Padahal faktanya, tidak semua ilmu pengetahuan bersifat demikian (Zarkasyi, 2018b).

Problem umat Islam bertambah kompleks di era westernisasi. Yang mana, penyebaran peradaban Barat turut pula membawa beberapa aspek negatif; yang didasari akan visi peradaban Barat tentang realitas dan kebenaran (Al-Attas, 2003; Armas, 2010; Zarkasyi, 2018a). Visi tersebut, senantiasa berubah dan berevolusi, dan menganggap bahwa segala nilai realitas dan kebenaran adalah relatif. Sejalan dengan itu, Nasr pun menyatakan bahwa peradaban Barat menceraikan sakralitas dari suatu realitas dunia fisik. Sehingga, corak peradaban; berikut ilmu pengetahuan dan sains turut berkembang namun membawa krisis kepada manusia modern (Nasr, 2005; Mirtaheri, 2012; Widiyanto, 2017).

Namun al-Attas menganggap, bahwa tidak semua hal dari Barat adalah negatif. Melainkan, ada beberapa hal-hal yang dapat diambil maupun diintegrasi dan diadapsi secara kritis ke dalam peradaban Islam. Hal-hal tersebut dapat diintegrasikan ke dalam Islam melalui proses intelektual kreatif yang disebut 'Islamisasi'; sehingga, hasilnya dapat disebut sebagai sains yang sudah 'islami'. Di masa selanjutnya, proses intelektual ini terus berproses hingga memunculkan apa yang disebut sebagai 'sains Islam' itu sendiri. Bagi Nasr, hal tersebut juga wajar. Karena suatu peradaban acapkali menyerap beberapa unsur dari peradaban lain dan mengadaptasikannya melalui worldview-nya masing-masing (Arif, 2008, pp. 238-239; Handrianto, 2019). Hal ini menambah relevansi pada tawaran al-Attas tentang hubungan antara Islam dan sains; di mana saat Islam bertemu dengan sains non Islam, perlu diadakan Islamisasi. Tawaran al-Attas, sejatinya dapat kita elaborasi melalui dua tahapan, yakni memahami tradisi sains di Barat dan Islam secara filosofis.

\section{Tradisi Sains Modern di Barat}

Sains memiliki tinjauan makna yang bersifat umum sekaligus khusus. Sains dalam bahasa Indonesia dimaknai sebagai ilmu atau ilmu pengetahuan (Bahasa, 2008, p. 420). Selain dari itu, sains dapat bermakna khusus sebagai ilmu pengetahuan alam, yaitu pengetahuan alam yang sistematik mengenai botani, 
zoologi, kimia, geologi, dan lainnya (Indonesia, 2008, p. 1244). Sains sebenarnya berasal dari bahasa Inggris, yaitu science yang berarti pengetahuan mengenai struktur dan tingkah laku dari alam dan dunia yang fisik, berdasarkan fakta yang dapat dibuktikan sepertidengan percobaan.(Oxford Advanced Learner's Dictionary, 2000, p. 1384; Cambridge Advanced Learner Dictionary, 2008, p. 1274) Albert Sidney Hornby, "Oxford Dictionary Language Matter," Oxford University Press, 2016, 1384; Cambridge, Cambridge Learner's Dictionary, Cambridge University Press, 2007, 1274. Makna sains (science) pada berbagai kamus bahasa aslinya lebih banyak bersifat konseptual yang mengacu seperti hal di atas. Namun ketika sains atau science diterjemahkan ke dalam bahasa Arab, ia bermakna 'ilm atau ilmu yang disetarakan dengan knowledge (Baalbaki, 1995, p. 775). Sedangkan secara konseptual, ilm dalam bahasa Arab berarti pengetahuan (idrak) mengenai sesuatu sesuai dengan hakikatnya (kebenarannya) yang meyakinkan (Ma'luf, 1908, p. 527) Ilmu juga bermakna pengetahuan terhadap sesuatu secara komprehensif dan sistematis, bukan hanya pengetahuan yang parsial atau sebagian (Al-Fairūzabadī, 2005, p. 624).

Terlihat dari perbedaan definisi secara linguistik di atas, bahwa pemaknaan sains menurut Barat dan Islam memiliki konsepsi masing-masing. Jika dilacak lebih jauh lagi, sains yang dimaknai sebagai science dalam tradisi keilmuan Barat tidaklah sama dengan sains yang dimaknai sebagai 'ilm yang ada dalam tradisi keilmuan Islam. Untuk itulah, sebelum mengungkap hubungan antara sains dan Islam, haruslah diperjelas terlebih dahulu macam-macam sains dari dua kutub yang mempergunakan istilah tersebut yaitu Barat dan Islam. Secara karakteristik, umumnya sains memiliki aspek-aspek khusus: (1) fokus/ subjek permasalahan yang terdefinsi, (2) menggunakan metodologi tertentu, (3) memiliki teori yang sudah terformulasi (4) akumulasi dari beberapa pengetahuan. Sehingga ia dapat didefinisikan sebagai "sebuah ilmu pengetahuan terorganisir yang muncul dari proses penelitian yang ketat terhadap suatu subjek materi yang telah diuji dan diselidiki oleh seorang ilmuwan menggunakan metode yang menghasilkan suatu teori" (Acikgenc, 1996, p. 35).

Ungkapan "sains modern" selalu dipahami bahwa sains adalah dari Barat yang mana sains tersebut telah melakukan revolusi sejak zaman ia dikekang di bawah kungkungan agama (Kristen). Sains Barat pun dengan karakternya juga memiliki sebuah sejarah dan revolusi tersendiri. Sains yang pada saat ini sudah 
memiliki worldview (Quthb, 1983; Al-Attas, 1995c; Doss, 2008; Sire, 2015) yang memiliki karakter penting : (1) studi kritis dan mendalam secara alami terhadap suatu aktivitas ilmiah dan (2) memiliki metode penjelasan ilmiah tertentu (Irzik and Nola, 2009). Sains dalam sejarahnya mengalami revolusi pada abad ke 16 dan 17. Paradigma sains barulah muncul dan memisahkan diri dari paradigma agama dan mitologi. Revolusi tersebut dipengaruhi oleh kepercayaan filosofis dan religious, yang mana agama pada saat itu selalu bertentangan dengan sains (Irzik and Nola, 2009; Gürol Irzik, 2014).

Sejarah sains di Barat, dalam perkembangannya lebih didominasi di tangan para matematikawan, fisikawan, dan ahli-ahli ilmu alam. Beberapa tokoh terkenal dalam kebangkitan sains Barat seperti Copernicus (1473-1543), Kepler (15711630), Galileo (1564-1642), hidup pada zaman kekuasaan Gereja di Eropa. Penerusnya adalah Newton (1643-1727), Gilbert (1540-1603), Harvey (15781657), Robert Boyle (1627-1691), dan Leeuwenhoek (1623-1723).(Russell, 2013, pp. 691-716) Barulah di zaman selanjutnya, estafet tersebut diraih oleh ilmuwan matematika, fisika, dan ilmu alam yang juga berbicara masalah filsafat seperti Descartes, Kant, dan Dilthey dan lainnya.(Borchert, 2006 vol. 7, p. 392) Dari pemikiran mereka itulah pemikiran mengenai sains menjadi berkembang, bahkan muncul anggapan bahwa "sains modern" adalah berasal dari Barat.

Implikasi bahwa Barat adalah kiblat sains modern menimbulkan beberapa hal penting. Hal tersebut akan terlihat jelas jika ditinjau dari paradigma(Given, 2008, p. 892; Kuhn, 2012, pp. 42-44) ilmu tersebut. Salah satunya adanya anggapan yang selama ini beredar, bahwa sains adalah "value-free" atau bebas nilai.(Hannabuss, 2006, p. 392) Gauch, seorang ilmuan menyatakan bahwa sains adalah netral karena didasari dengan metode ilmiah yang dikuatkan oleh pembuktian dengan sebuah realitas. Gauch menganggap sains sebagai interogasi terhadap alam lantas kemudian membuat kesimpulan darinya. Sains hanya terbatas pada hal yang tampak dalam realitas fisik (Irzik and Nola, 2009). Berpedoman pada "tujuh karakter sains"-nya, (Gauch, 2009) Gauch menyimpulkan bahwa sains merupakan hal yang netral. Hal tersebut, nyata mendatangkan kritik dari ilmuwan setelahnya.

Secara metodis, Matthew Orr menyatakan bahwa agama dan sains menghasilkan disiplin ilmu yang berbeda dan prosedur operasional yang berbeda. 
Sebagai contoh bahwa keyakinan mendapat sedikit bagian dalam sains, sedangkan agama tidak hanya terbatas pada hal-hal yang dapat diobservasi secara empiris (Orr, 2006) Emile Durkheim (1982). menyatakan bahwa jika seorang peneliti ingin mencapai kebenaran dari sebuah penelitian, ia harus mengobservasi hakekat realitas apa adanya untuk menjaga objektivitas temuan. Karena itu, secara metodologis, seorang peneliti menggunakan metodologi eksperimen-empirik untuk menjamin agar temuan yang diperoleh betul-betul objektif dalam menggambarkan keadaan yang sebenarnya. Mereka mencari ketepatan yang tinggi, pengukuran yang akurat, dan juga menguji hipotesis dengan jalan melakukan analisis terhadap bilanganbilangan yang berasal dari pengukuran (Muslih, 2004, p. 91).

Kerlinger (1973) dari aliran positivisme menyatakan bahwa sains - ilmu pengetahuan, objek sains, maupun pernyataan-pernyataan saintifik haruslah memiliki syarat-syarat sebagai berikut: dapat di/ter amati (observable), dapat di/ terulang (repeatable), dapat di/terukur (measurable), dapat di/teruji (testable) dan dapat di/terramalkan (predictable). Paradigma tersebut telah menjadi pegangan dalam mengungkap kebenaran realitas, karena itulah paradigma sains tersebut bersifat kuantitatif dan operasional (Muslih, 2004, p. 92). Namun, di masa selanjutnya; paradigma cenderung berubah dan berkembang. Hal ini menegaskan bahwa sains dalam aliran positivisme bukanlah tanpa kelemahan. Kritik kepadanya justru datang dari Barat itu sendiri, karena aliran positivisme hanya mengandalkan pengamatan langsung terhadap objek yang diteliti. Realitas dalam kenyataan kadangkala sesuai dengan hukum alam, namun kadang realitas juga tidak selalu dapat dilihat secara benar. Oleh karena itu, pendekatan eksperimental melalui observasi tidaklah cukup tetapi harus menggunakan metode triangulation (Given, 2008, p. 892) yaitu penggunaan bermacam-macam metode, sumber data, peneliti dan teori dalam membuktikan kebenaran penelitian tersebut (Muslih, 2004, p. 92).

Tidak jauh dari itu, kedua aliran tersebut juga mendapat kritik dari Konstruktivisme (Kukla and others, 2000; Borchert, 2006, p. 471; Pfadenhauer and Knoblauch, 2018) dan Critical Theory.(Chirkov and Anderson, 2018). Hal ini muncul setelah sejumlah ilmuwan menolak tiga prinsip dasar positivisme: (1) ilmu merupakan upaya mengungkap realitas; (2) hubungan antara subjek dan objek penelitian harus dapat dijelaskan; (3) hasil temuan memungkinkan untuk digunakan karena itu akan menumbuhkan bangunan teori atas realitas 
majemuk dari masyarakatnya, dengan demikian, tidak ada suatu realitas yang dapat dijelaskan secara tuntas oleh suatu ilmu pengetahuan karena ia bersifat konfliktual dan dialektis (Muslih, 2004, p. 95) Implikasi dari hal tersebut, bahwa menurut konstruksivisme baik sains maupun ilmu pengetahuan merupakan suatu konstruksi yang terbatasi: oleh rasionalitas, hakikat manusia, atau ilmu itu sendiri, sehingga kebenarannya merupakan hal yang relatif atau plural (Blackburn, 2013, p. 184).

Sedangkan critical theory, meski bukan sebuah ideologi, ia merupakan aliran pengembangan keilmuan yang didasarkan pada suatu konsepsi kritis terhadap berbagai pemikiran dan pandangan yang sebelumnya ditemukan sebagai paham keilmuan lainnya. Aplikasi dari teori ini pada pendekatan filosofis madzhab Frankfrut. Latar belakangnya adalah filsafat Hegel dan Marx yang melihat ketidaksempurnaan budaya sebagai cacat rasionalitas, lantas kemudian mengembangkan rasio baru dan penataan sosial yang musrni. Teori kritis bekerja secara dialektis, yaitu menelusuri kontradiksi dalam tata sosial yang ada (Blackburn, 2013, pp. 205-206; Bronner, 2017). Critical theory juga mengkritisi bahwa paradigma Barat mengandung beberapa problem yang butuh dikaji: (1) problem prosedur; (2) perumusan kembali standar dan aturan keilmuan sebagai logika dalam konteks historis; (3) dikotomi objek dan subjek; (4) keberpihakan ilmu dalam interaksi sosial. Sehingga, baik itu sains, maupun ilmu pengetahuan apapun merupakan hasil dari pemikiran manusia yang tidak bisa bebas dari nilai atau value-free (Muslih, 2004, p. 96; Bronner, 2017). Kenyataan telah diuraikan oleh al-Attas, bahwa sejatinya ilmu dan sains dari Barat memiliki dimensi yang saling berdialektis, sehingga tidak menemukan paradigma yang mapan. Hal ini diafirmasi oleh Thomas Kuhn, dengan istilah 'Shifting Paradigm'.

Berdasarkan hal di atas, kita dapat mengambil kesimpulan kritis mengenai pandangan al-Attas tentang makna dan 'relativitas' paradigma sains dalam tradisi keilmuan Barat. Banyak terlihat diskursus antara para ilmuwan itu sendiri, dan memang inilah semangat keilmuan Barat yang selalu berubah. Hal ini jika ditelusuri lebih lanjut, ternyata merupakan implikasi dari karakter epistemologi Barat itu sendiri. Secara fundamental, pemikiran sains Barat modern bersifat realisme dan rasionalisme. Karena itulah, sains merupakan produk dari pikiran manusia, yang mana strukturnya adalah hukum berfikir dan hukum yang ada di dunia luar pikiran tersebut. Aspeknya adalah subjektif dan objektif, keduanya 
sama dalam kedudukannya dan tidaklah mungkin bahwa hukum alam ini akan berubah (Bachelard, 1984, p. 2; Smith, 2016).

Karena sains merupakan barat yang rasionalis empiris sudah tentu dalam epistemologinya tidak menerima otoritas (wahyu) dan intuisi, namun hanya mereduksi otoritas dan intuisi kepada nalar dan pengalaman indrawi selanjutnya alam ini tereduksi hanya sebagai realitas dari kekuatan alamiah saja (Al-Attas, 1985, pp. 15-16, 1995b, p. 26; Alfi, 2018). Hal tersebut juga berimplikasi pada konsep sains dan ilmu pengetahuan dalam pemikiran Barat. Bahwa sains modern merupakan satu-satunya ilmu yang otentik karena langsung bersangkut paut dengan fenomena, yang mana fenomena akan selalu berubah sepanjang zaman disertai juga dengan nilai kebenaran dari realitasnya (Al-Attas, 2001, p. 26, 2003; Adas, 2015; Makarova et al., 2019). Sehingga alam dalam perspektif ini merupakan sistem yang berdiri sendiri dan kekal (tidak diciptakan) serta berkembang menurut hukumnya sendiri. Pandangan filosofis ini tentunya menolak peran Tuhan dan keberadaanNya (Al-Attas, 1995a, p. 115, 2001, p. 27).

\section{Tradisi Sains dalam Islam}

Untuk memperjelas hubungan antara Sains dan Islam diperlukan kajian mendalam mengenai makna Islam itu sendiri. Hal ini dilakukan oleh al-Attas secara lengkap dalam buku Islam dan Filsafat Sains. Islam adalah sebuah nama agama yang jika ditelusuri makna ontologinya dalam bahasa Arab berarti keselamatan atau ketaatan kepada perintah tanpa menolaknya (Ma'Luf, 1986, p. 347). Islam dari kata aslama berarti masuk kepada Islam, yakni mengikhlaskan din kepada Allah(Al-Najjar, 2011, p. 446) atau juga berserah diri kepada Allah (Al-Fairūzabadī, 2005, p. 1122). Berakar dari kata salima-yaslamu yang berarti selamat, berserah diri dan rela kepada suatu hukum (Ma'Luf, 1986, p. 347; AlNajjar, 2011, p. 446) dan aslama-yuslimu yaitu menampakkan ketaatan dan mengikuti syariat yang dibawa oleh Rasulullah SAW, taat kepada perintah Allah dan mengikhlaskan diri untuk beribadah kepada Allah (Ibnu Mandzur, 1999 vol. 12 , p. 239). Sedangkan muslim adalah orang yang beragama Islam dan berserah diri (Ma’Luf, 1986, p. 347) dan menerima ajaran Rasulullah SAW (Ibnu Mandzur, 1999 vol. 12, 294).

Umumnya, Islam dianggap sebagai agama yang kadangkala diterjemahkan 
menjadi religion atau dalam bahasa Arab berarti din. Penerjemahan dan pemaknaan ini sebenarnya perlu dikaji lebih mendalam. Perbedaan kata dan bahasa akan sangat mempengaruhi keyakinan dan worldview manusia dalam memahami konsepsi segala sesuatu (Zarkasyi, 2016, pp. 16-17). Jika Islam dianggap sebagai agama, dalam bahasa Indonesia, ia berarti sistem yang mengatur tata keimanan (kepercayaan) kepada Tuhan yang Maha Kuasa, tata peribadatan, dan tata kaidah yang bertalian dengan pergaulan manusia dan manusia serta lingkungannya dengan kepercayaan itu (Indonesia, 2008, p. 18). Sedangkan religion berarti kepercayaan terhadap keberadaan Tuhan yang berimplikasi pada menjalankan ritual untuk menyembahnya dan adanya berbagai ajaran yang berdimensi spiritual (Oxford Advanced Learner's Dictionary, 2000, p. 1304; Cambridge Advanced Learner Dictionary, 2008, p. 1202).

Jika Islam dianggap sebagai din, maka maknanya juga akan lain. Kata din merupakan kata bahasa Arab daana-yadiinu yaitu pemberian untuk jangka waktu tertentu, (Al-Fairūzabadī, 2005, p. 1198) memberikan harta untuk tempo tertentu atau memberikan hutang, sedangkan dayn adalah hutang. Dayn dalam makna din juga dimaknai sebagai keberhutangan kepada dayyan yaitu Allah (Al-Najjar, 2011, p. 307). Kata tersebut juga mengacu pada istilah din berarti ketaatan, berpegang teguh, (Ma'Luf, 1986, p. 231) dan keterikatan untuk menjadi hamba. (Al-Fairūzabadī, 2005, p. 1198) Atau juga diyanah dalam Islam berartikeyakinan dengan hati, mengikrarkan dengan lisan, dan mengerjakan rukunnya secara jasmani (Al-Najjar, 2011, p. 307). Dalam berbagai tafsir ayat al-Qur'an, din yang terlengkap, terbaik, dan diridhoi adalah ber-Islam kepada Allah ('al-Qur'an: 4:83-85; 4:125; 6:161; 9:29; 24:2; 98:5; dan 110:2.', no date). Sedangkan makna utama din secara filosofis disimpulkan oleh al-Attas menjadi empat unsur, yaitu keberhutangan manusia secara eksistensial kepada Allah, penyerahan diri manusia kepada Allah, pelaksanaan kekuasaan pengadilan, dan suatu cerminan dari kecenderungan alami manusia atau fitrah yang kembali pada Hari Perjanjian pertama (Wan Daud, 2003, pp. 191-192).

Menurut Jujun S. Suriasumantri, penerjemahan kata sciene menjadi ilmu atau ilmu pengetahuan memiliki masalah yang pokok. Selanjutnya, ia mengusulkan kata padaan untuk ilmu adalah knowledge, sedangkan science adalah ilmu pengetahuan (Suriasumantri, 1984, pp. 291-299). Demikian pula, Syed Naquib al-Attas juga memberikan catatan khusus mengenai penyebutan 
sains sebagai ilmu tersebut dikarenakan ilmu merupakan istilah dari bahasa Arab yaitu 'ilm. Sedangkan makna 'ilm dalam bahasa Arab mencakup ma’rifah (ilmu pengenalan) dan ilmu pengetahuan (sains). Karena keduanya memiliki implikasi masing-masing (Al-Attas, 1995a, pp. 114-115; Adi Setia, 2003).

Sains Islam secara khusus dapat didefinisikan sebagai aktifitas saintifik atau ilmiah yang memiliki dasar atau berpedoman pada Islamic worldview (yaitu penggunaan konsep "natural" secara Islamiy) dan merupakan pengejawentahan secara langsung dari skema konseptual saintifik yang Islamiy (Acikgenc, 1996, pp. 38-40; Acikgence, 2012; Açlikgenç, 2016; Bakar, 2016a) Tentunya dalam pencapaian kegiatan saintifik/ilmiah ini, Islam juga menekankan adanya sumbersumber dan metode ilmu tersebut. Islam memandang sains yang bersifat fisik tidak hanya pada tataran lahiriyah saja, namun juga adanya tujuan, kebenaran, dan pengakuan wahyu sebagai satu-satunya suber ilmu tentang realitas dan kebenaran yang terkait dengan makhluk dan khaliknya (Al-Attas, 2001, p. 33; Zarkasyi, 2016). Artinya, dalam melakukan kegiatan saintifik, para ilmuwan muslim yang berpedoman al-Qur'an dan Hadits akan dapat melahirkan produk sains yang membawa maslahat bagi kehidupan manusia, baik jangka panjang maupun jangka pendek.

Sains menurut Islam secara pokok merupakan sebuah jenis ta'wil atau interpretasi alegoris dari benda-benda empiris yang menyusun dunia alam. Sains semacam itu harus mendasarkan dirinya secara tetap pada tafsir atau interpretasi dari penampakan atau makna yang jelas dari benda-benda dalam alam. Penampakan dan makna mereka yang jelas berurusan dengan tempat mereka di dalam sistem hubungan dan tempat mereka menjadi nampak pada pemahaman kita ketika batas kebenaran dari arti mereka dikenali. Saat ini, filsafat modern telah menjadi penafsir sains, dan mengorganisir hasil sains alam dan sosial ke dalam sebuah pandangan dunia. Interpretasi itu pada gilirannya menentukan arah yang diambil sains dalam studi alam. Adalah interpretasi tentang pernyataan ini dan kesimpulan umum sains dan arah sains sepanjang garis yang ditawarkan oleh interpretasi yang harus diletakkan pada evaluasi kritis (Al-Attas, 2001, pp. 15-16; Iqbal, 2017; Toby E Huff, 2017).

Dalam Islam, sains sangat terikat dengan ilmu pengetahuan dan iman. Karena 
sifat dari kandungan proposisionalnya sama dengan sifat dari prinsip pertama logika dan pengetahuan metafisika, etika, dan estetika; maka dengan sendirinya dalam diri subjek ia bertindak sebagai cahaya yang menerangi segala sesuatu. Bahwa iman adalah suatu visi yang menempatkan semua data dan fakta dalam perspektif yang sesuai dengan, dan perlu bagi, pemahaman yang benar atas mereka. Ia adalah dasar bagi penafsiran yang rasional atas alam semesta sebagaimana ia merupakan prinsip utama dari akal, tidak mungkin bersifat non-rasional dan bertentangan dengan diri sendiri (Al-Faruqi, 1992, p. 42; Al-Ghazali, 2003, pp. 62-63). Alam semesta yang menjadi sumber realitas penalaran sains merupakan gambaran yang tak terpisahkan dari wujud Allah. Karena dibalik wujud dan realitas alam semesta ini terdapat dimensi metafisik dan tujuan dari penciptaannya. Sains dalam Islam ditujukan untuk melakukan pembuktian terhadap isyarat-isyarat untuk pencarian ilmu sebagaimana tertera dalam al-Qur'an (Bakar, 2005, 2016b). Hal inilah, yang menjadi tawaran paradigmatik al-Attas tentang Sains Islam. Yang mana, dimulai dari uraiannya secara filosofis tentang makna sains dan ilmu beserta distingsinya.

\section{Simpulan}

Di tengah maraknya kajian tentang hubungan sains dan agama; banyak ilmuwan telah berusaha menjelaskannya. Penjelasan tersebut, memiliki karakteristik yang beragam, serta menunjukkan paradigma, metode, serta latar belakang akademiknya. Namun yang menarik, terdapat titik temu yang dapat dijelaskan. Misalnya, tawaran integrasi ilmu menegaskan urgensi kritik terhadap sains Barat sekaligus menemukan aspek interkoneksi pada ilmu pengetahuan agar dapat 'diserap' ke dalam Islam. Dalam Islamisasi, aspek kritik kepada sains Barat juga dilakukan, untuk memilah aspek ideologis pada sains Barat yang pada banyak aspeknya dapat diintegrasikan ke dalam Islam. Dan di masa selanjutnya, akan dikembangkan melalui kegiatan intelektual kreatif menuju Sains Islam.

Aspek yang lebih esensial lagi, antara paradigma integrasi dan Islamisasi sejatinya sama-sama didasari oleh 'pandangan alam' Islam (Islamic worldview). Adapun perbedaannya, paradigma integrasi lebih menekankan agar agama mau membuka diri kepada ilmu pengetahuan sejalan dengan sains yang harus mau membuka diri untuk menjelaskan alam secara religius. Hal ini sejatinya telah terjadi di masa awal pertemuan Islam dengan peradaban lainnya. Sebagaimana saat Umar bin Khattāb mengintegrasikan sistem administrasi Persia dan Romawi 
ke dalam peradaban Islam. Sedangkan paradigma Islamisasi, diuraikan oleh alAttas dengan pendekatan filosofis dengan Sains Islam sebagai tujuan akhirnya. Kita dapat melihat Islamisasi seolah merupakan pemutakhiran dari proses integrasi ilmu ke dalam Islam. Buktinya, hal-hal yang telah terintegrasi di dalam Islam pada awal pertemuannya dengan peradaban non-Islam dilanjutkan melalui kegiatan intelektual kreatif yang menghasilkan Sains Islam yang benar-benar baru secara asumsi dasar hingga metodenya. Jika merujuk pada penjelasan Amin Abdullah tentang integrasi-interkoneksi, kita dapat melihat secara utuh bahwa integrasi keilmuan membuka ruang untuk metodologi hingga program riset untuk Sains Islam itu sendiri. Artinya, tawaran al-Attas dapat dikategorikan sebagai ruanganruangan untuk mem-fusikan worldview Islam ke dalam Sains, sehingga dapat melahirkan Sains Islam yang filosofis.

\section{Daftar Referensi}

Abdullah, M. A. (2014) 'Religion, science and culture: An integrated, interconnected paradigm of science', Al-Jamiah. doi: 10.14421/ajis.2014.521.175-203.

Açlikgenç, A. (2016) 'Philosophy of Science in Epistemological Perspective', in Islamic Perspectives on Science and Technology. Springer, pp. 59-74.

Acikgenc, A. (1996) Islamic Science: Towards a Definition. Kuala Lumpur: ISTAC. Acikgence, A. (2012) 'Model for the Development of Science and Humanities Curriculum in Islamic Universities', TSAQAFAH. doi: 10.21111/tsaqafah. v8i1.19.

Adas, M. (2015) Machines as the measure of men: Science, technology, and ideologies of Western dominance. Cornell University Press.

Adi Setia (2003) 'Al-Attas Philosophy of Science An Extended Outline', Islam \& Science, 1(2), pp. 165-214.

Al-Alam, I. (2017a) 'Karir dan Karya-karya al-Attas', Islamia: Jurnal Pemikiran dan Peradaban Islam edisi: Tafsir-tafsir Pemikiran al-Attas: Metafisika, Epistemologi, Bahasa, Pendidikan, Sejarah Alam Melayu, XI(2), pp. 7-8.

Al-Alam, I. (2017b) 'Karir dan Karya-karya al-Attas', Islamia: Jurnal Pemikiran 
dan Peradaban Islam edisi: Tafsir-tafsir Pemikiran al-Attas: Metafisika, Epistemologi, Bahasa, Pendidikan, Sejarah Alam Melayu.

al-Attas, S. M. N. (1995) 'Islam: The Concept of Religion and the Foundation of Ethics and Morality', in Prolegomena to The Metaphysics of Islam: an Exposition of the Fundamental Elements of the Worldview of Islam. Kuala Lumpur: International Institute of Islamic Thought and Civilization (ISTAC), p. 358.

Al-Attas, S. M. N. (1985) 'Islam: The Concept of Religion and the Foundation of Ethics and Morality', in Islam, Secularism and The Philosophy of the Future, pp. 47-90.

Al-Attas, S. M. N. (1995a) 'Islam and The Philosophy of Science', in Prolegomena to The Metaphysics of Islam: an Exposition of the Fundamental Elements of the Worldview of Islam. Kuala Lumpur: International Institute of Islamic Thought and Civilization (ISTAC), p. 385.

Al-Attas, S. M. N. (1995b) Islam dan Filsafat Sains. Bandung: Penerbit Mizan.

Al-Attas, S. M. N. (1995c) Prolegomena to the Metaphysics of Islam, Kuala Lumpur: International Institute of Islamic Thought and Civilization.

Al-Attas, S. M. N. (2001) Islam dan Filsafat Sains Prolegomena to The Metaphysics of Islam. Kuala Lumpur: ISTAC.

Al-Attas, S. M. N. (2003) 'Islam and the Challenge of Modernity: Divergence of Worldviews', in Hershock, Peter D., Stepaniants, Marietta, T. Ames, R. (ed.) Technology and Cultural Values: On the Edge of the Third Millennium. I. Honolulu.

Al-Fairūzabadī, M. al-D. M. Y. (2005) Qamus al-Muhith (tahqiq Maktab Tahqiq al-Turats Fiy Muassasati al-Risalah). Beirut: al-Resalah Publisher.

Al-Faruqi, I. R. (1992) l-Tawhìd: Its Implications for Thought and Life. IV. Virginia: International Institute of Islamic Thought.

Al-Ghazali, A. H. M. ibn M. (2003) Al-Munqidz min al-Daläl tahqiq Jamīl Shaliban. Beirut: Dar al-Andalus.

Al-Najjar, I. M. A. al-Z. H. A. al-Q. M. (2011) Majma' al-Lughah al-'Arabiyah bi al-Qahirah: Mujjam al-Wasith. Cairo: Maktabah Shurouq ad-Dauliyyah. 
'al-Qur'an: 4:83-85; 4:125; 6:161; 9:29; 24:2; 98:5; dan 110:2.' (no date).

Alatas, S. H. (2013) The myth of the lazy native: A study of the image of the Malays, Filipinos and Javanese from the 16th to the 20th century and its function in the ideology of colonial capitalism, The Myth of the Lazy Native: A Study of the Image of the Malays, Filipinos and Javanese from the 16th to the 20th Century and its Function in the Ideology of Colonial Capitalism. doi: 10.4324/9780203043271.

Alfi, L. A. (2018) 'Konsep Ilmu Menurut Syed Muhammad Naquib Al-Attas (Analisis buku Islam Dan Filsafat Sains)', Tasfyah. doi: 10.21111/tasfiyah. v2i2.2580.

Ardiansyah, M. et al. (2017) 'The Concept of Adâb by Syed Muhammad Naquib al-Attas and Its Relevance to Education in Indonesia', International Journal of Islamic Education Ta'dibuna. doi: 10.32832/ikjss.v1i1.

Arif, S. (2008) Orientalis \& diabolisme pemikiran. Jakarta: Gema Insani.

Armas, A. (2010) 'Westernisasi dan Islamisasi Ilmu', in Shubhi, T. (ed.) Membangun Peradaban dengan Ilmu. Depok: Kalam Indonesia-UI.

Baalbaki, R. (1995) Al-Mawrid Qamus 'Arabiy Injiliziy. Beirut: Daar al-Ilmiy Lil Malayin.

Bachelard, G. (1984) 'The new scientific spirit'.

Bahasa, T. P. (2008) Tesaurus Bahasa Indonesia Pusat Bahasa. Jakarta: Departemen Pendidikan Nasional.

Bakar, O. (2005) 'History of Islamic Science', Islam \& Sains.

Bakar, O. (2016a) 'Agama dan Sains dalam Perspektif Islam', in Arif, S. (ed.) Islamic Science: Paradigma, Fakta, dan Agenda. 1st edn. Jakarta: INSISTS Jakarta.

Bakar, O. (2016b) 'Science and Technology for Mankind's Benefit: Islamic Theories and Practices - Past, Present, and Future', in Islamic Perspectives on Science and Technology. doi: 10.1007/978-981-287-778-9_3.

Blackburn, S. (2013) 'Kamus Filsafat', Yogyakarta: Pustaka Pelajar.

Borchert, D. M. (2006) Encyclopedia of philosophy. Thomson Gale/Macmillan Reference USA. 
Bronner, S. E. (2017) 'Critical theory and resistance: On antiphilosophy and the philosophy of praxis', in The Palgrave Handbook of Critical Theory. Springer, pp. $17-42$.

Brooke, J. H. (2014) Science and religion: Some historical perspectives, Science and Religion Some Historical Perspectives. doi: 10.1017/CBO9781107589018.

Cambridge (2007) Cambridge Learner's Dictionary, Cambridge University Press.

Cambridge Advanced Learner Dictionary (2008) 'Cambridge Advanced Learner Dictionary', Korea Tesol Journal.

Chirkov, V. and Anderson, J. (2018) 'Statistical positivism versus critical scientific realism. A comparison of two paradigms for motivation research: Part 1. A philosophical and empirical analysis of statistical positivism', Theory \& Psychology. SAGE Publications Sage UK: London, England, 28(6), pp. 712736.

Doss, C. (2008) 'Naming the Elephant: Worldview as a Concept', Mission Studies, 25(2), pp. 302-303. doi: 10.1163/157338308x365567.

Dzulhadi, Q. N. (2015) 'Islam sebagai Agama dan Peradaban', TSAQAFAH, 11(1), p. 151. doi: 10.21111/tsaqafah.v11i1.258.

Ellis, T. B. (2012) 'Growing up amid the religion and science affair: A perspective from indology', Zygon. doi: 10.1111/j.1467-9744.2012.01276.x.

Fletcher, E. (2015) 'Interpreting qualitative data', International Journal of Research \& Method in Education. doi: 10.1080/1743727x.2015.1066173.

FYFE, A. (2005) 'JOHN L. HEILBRON (ed.), The Oxford Companion to the History of Modern Science. Oxford and New York: Oxford University Press, 2003. Pp. xxviii 941. ISBN 0-19-511229-6. £80.00 (hardback).', The British Journal for the History of Science. Cambridge University Press, 38(3), pp. 351-353. doi: 10.1017/S0007087405227279.

Gauch, H. G. (2009) 'Science, worldviews, and education', Science \& Education. Springer, 18(6-7), pp. 667-695.

Gibson, W. and Brown, A. (2011) Working with Qualitative Data, Working with Qualitative Data. doi: 10.4135/9780857029041. 
Given, L. M. (ed.) (2008) The SAGE Encyclodpedia of Qualitative Research Methods. California: SAGE Publication Inc.

Von Grunebaum, G. E. (2013) Islam: Essays in the nature and growth of a cultural tradition, Islam: Essays in the Nature and Growth of a Cultural Tradition. doi: $10.4324 / 9781315888286$.

Gürol Irzik, R. N. (2014) 'New Directions for Nature of Science Research; In: Matthews M. (eds) International Handbook of Research in History, Philosophy and Science TeachingIn':, International Handbook of Research in History, Philosophy and Science Teaching. doi: 10.1007/978-94-007-7654-8.

Handrianto, B. (2019) 'Islamisasi Ilmu Pengetahuan Di Era Revolusi Industri 4.0 (Makna Dan Tantangannya)', The Annual Conference on Islamic Education and Social Science, 1(1), pp. 1-13. Available at: http://pkm.uika-bogor.ac.id/ index.php/ACIEDSS/article/view/483.

Hannabuss, S. (2006) 'Encyclopedia of Philosophy (2nd edition)2006297Editorin-chief Donald M. Borchert. Encyclopedia of Philosophy (2nd edition) . Farmington Hills, MI: Macmillan Reference 2006. \$995, ISBN: 002 865780210 vols Also published simultaneously as an e-book (IS', Reference Reviews. doi: 10.1108/09504120610687056.

Hidayatullah, S. (2019) 'Agama dan Sains: Sebuah Kajian Tentang Relasi dan Metodologi', Agama dan Sains: Sebuah Kajian Tentang Relasi dan Metodologi, 29(1), pp. 102-133. doi: 10.22146/jf.30246.

Hornby, A. S. (2016) 'Oxford dictionary language matter', Oxford University Press. HOUGHTON, J. (2011) 'Global Warming, Climate Change and Sustainability', The John Ray Initiative.

Huff, Toby E. (2017) The rise of early modern science: Islam, China, and the West: Third edition, The Rise of Early Modern Science: Islam, China, and the West: Third Edition. doi: 10.1017/9781316417805.

Huff, Toby E (2017) The rise of early modern science: Islam, China, and the West. Cambridge University Press.

Ibnu Mandzur, M. bin M. bin A. A. al-F. J. al-D. (1999) Lisān al-Arab. Beirut: 
Daar al-Shadir.

Indonesia, T. P. K. B. (2008) Kamus Besar Bahasa Indonesia. Jakarta: Pusat Bahasa. Iqbal, M. (2017) 'Islam and Modern Science: Questions at the Interface', in God, Life, and the Cosmos. Routledge, pp. 25-64.

Irzik, G. and Nola, R. (2009) 'Worldviews and their relation to science', in Science, Worldviews and Education. doi: 10.1007/978-90-481-2779-5_4.

Ismail, S. (2017) 'Al-Attas' Philosophy of Islamic Education', in Aricis Proceedings, pp. 341-350. Available at: http://jurnal.ar-raniry.ac.id/index.php/aricis/ article/view/957.

Karamustafa, A. T. (2017) '16. Islamic Dìn as an Alternative to Western Models of "Religion", in Religion, Theory, Critique. doi: 10.7312/king14542-018.

Kuhn, T. S. (2012) The structure of scientific revolutions. University of Chicago press.

Kukla, A. and others (2000) Social constructivism and the philosophy of science. Psychology Press.

Ma'luf, L. (1908) Al-Munjid fì al-Lughah wa al-A'lam. 19th edn. Beirut: alMathba'ah al-Katholikiyah Publisher.

Ma'Luf, L. (1986) 'al-Munjid fi al-Lughah wa al-A'lam', Beirut: Dar al-Masyriq.

Makarova, E. V et al. (2019) 'Divergence of supreme values of Russian world and western civilization social and philosophical analysis', European Journal of Science and Theology, 15(3), pp. 97-107.

Maulana, M. F. (2018) 'Islamization Versus Deislamization of Language a Case of Indonesian Vocabularies', KnE Social Sciences, pp. 473-483.

Mirtaheri, S. A. (2012) 'In Search of the Sacred: A Conversation with Seyyed Hossein Nasr on his Life and Thought', Iranian Studies. doi: 10.1080/00210862.2012.673837.

Muhammad, D. N. P. H. (2009) A Critical Study of the Educational System in Brunei Darussalam in the Light of Al-Attas' Philosophy of Education. The University of Birmingham.

Muslih, M. (2004) FILSAFAT ILMU; Kajian atas Asumsi Dasar, Paradigma, dan 
Kerangka Teori Ilmu Pengetahuan. LESFI.Muslih, M. (2016) 'Al-Qur'an dan Lahirnya Sains Teistik', TSAQAFAH, 12(2). doi: 10.21111/tsaqafah. v12i2.756.

Muslih, M. (2017a) 'Rekonstruksi Metodologi Pengembangan Sains Berbasis Agama', KALAM, 11(2), pp. 267-298. doi: https://doi.org/10.24042/klm. v11i2.1795.

Muslih, M. (2017b) 'Rekonstruksi Metodologi Pengembangan Sains Berbasis Agama', KALAM, 11(2), p. 267. doi: 10.24042/klm.v11i2.1795.

Muslih, M. (2019) 'Toward Theology of Science: Philosophical Reflection On The Development Of Religion-Based Science', KALAM, 13(1), pp. 1-24. doi: https://doi.org/10.24042/klm.v13i1.3953.

Muslih, M. (2020) 'Filsafat Ilmu Imre Lakatos dan Metodologi Pengembangan Sains Islam', Tasfiyah. doi: 10.21111/tasfiyah.v4i1.3962.

Nasr, S. H. (2005) The Need For a Sacred Science, The Need For a Sacred Science. doi: $10.4324 / 9780203990599$.

Nurdin, A. A. (2016) 'Revisiting discourse on Islam and state relation in Indonesia: the view of Soekarno, Natsir and Nurcholish Madjid', Indonesian Journal of Islam and Muslim Societies, 6(1), pp. 63-92.

Orr, M. (2006) 'What is a scientific world view, and how does it bear on the interplay of science and religion?', Zygon. doi: 10.1111/j.1467-9744.2005.00748.x.

Oxford Advanced Learner's Dictionary (2000) Oxford Advanced Learner's Dictionary (International Student's Edition), Oxford University Press.

Pfadenhauer, M. and Knoblauch, H. (2018) Social Constructivism as Paradigm?: The Legacy of The Social Construction of Reality. Routledge.

Quthb, S. (1983) Khashaish al-Tashawwur al-Islamiy wa Muqawwimatuhu,. Beirut: Daar al-Masyriq Publisher.

Russell, B. (2013) History of western philosophy: Collectors edition. Routledge.

Salomon, N. (2013) 'Evidence, Secrets, Truth: Debating Islamic Knowledge in Contemporary Sudan', Journal of the American Academy of Religion. Oxford University Press, 81(3), pp. 820-851. 
Sire, J. W. (2015) 'Worldview definitions: From Dilthey to Naugle', Naming the Elephant: Worldview as a concept.

Smith, R. C. (2016) Gaston Bachelard, Revised and Updated: Philosopher of Science and Imagination. Suny Press.

Suriasumantri, J. S. (1984) Filsafat Ilmu: Sebuah Pengantar. Jakarta: Sinar Harapan.

Wan Daud, W. M. N. (2003) Filsafat dan Praktik Pendidikan Islam Syed Muhammad Naquib al-Attas (penerjemah: Hamid Fahmy, M. Arifin Ismail, dan Iskandar Amel). 1st edn. Bandung: Penerbit Mizan.

Widiyanto, A. (2017) 'Traditional science and scientia sacra: Origin and dimensions of Seyyed Hossein Nasr's concept of science', Intellectual Discourse.

Widodo, A. (2009) 'Syed Muhammad Naquib al-Attas' Semantic Reading of Islam as Din', Al-Jamiah: Journal of Islamic Studies, 47(1), p. 135. doi: 10.14421/ ajis.2009.471.135-163.

De Witt, A. et al. (2016) 'A new tool to map the major worldviews in the Netherlands and USA, and explore how they relate to climate change', Environmental Science and Policy. doi: 10.1016/j.envsci.2016.05.012.

Ynalvez, M. A. and Shrum, W. M. (2015) 'Science and Development', in International Encyclopedia of the Social \& Behavioral Sciences: Second Edition. doi: 10.1016/B978-0-08-097086-8.85020-5.

Zaprulkhan, Z. (2013) 'MEMBANGUN RELASI AGAMA DAN ILMU PENGETAHUAN', KALAM, 7(2), pp. 259-272. doi: 10.24042/klm. v7i2.465.

Zarkasyi, H. F. (2016) 'Islamic Worldview sebagai Paradigma Sains Islam', in Arif, S. (ed.) Islamic Science: Paradigma, Fakta, dan Agenda. Jakarta: INSISTS Jakarta.

Zarkasyi, H. F. (2018a) 'Knowledge and knowing in islam: A comparative study between nursi and al-attas', Global Journal Al-Thaqafah.

Zarkasyi, H. F. (2018b) 'Knowledge and knowing in Islam: a comparative study between Nursi and al-Attas', Global Journal Al-Thaqafah. 